\title{
Construction of Solar Radiation Simulation Database and Solar Radiation Simulation System using GIS and Application to the Agriculture Field
}

\author{
Atsushi Shiota ${ }^{1 *}$, Ayumi Tada ${ }^{2}$, Shuhei Yamada ${ }^{2}$, Kokichi Yokozawa ${ }^{1}$, Thongchart Kerdphol ${ }^{1}$ and Yasunori Mitani $^{1}$ \\ ${ }^{1}$ Department of Electrical and Electronics Engineering, Kyushu Institute of Technology, Japan \\ ${ }^{2}$ City of Kitakyushu, Japan \\ *Corresponding Author: Atsushi Shiota, Department of Electrical and Electronics Engineering, Kyushu Institute of Technology, Japan.
}

Received: August 19, 2019; Published: September 05, 2019

DOI: 10.31080/ASAG.2019.03.0636

\begin{abstract}
Japan has introduced a fixed power purchase price system in recent years due to the rapid growth of solar power generation and the reduction costs of photovoltaic panels. As a result, it is expected that introduction of a solar power generation system will continue growing in the nearly future. As the amount of solar power generation is influenced by weather and shadows, various problems are occurring from the effect of weather and shadows. On the other hand, the amount of solar radiation affects not only photovoltaic power generation but also the growth of plants such as fruits and vegetables.

Our research team has been conducting yearly and monthly solar radiation analysis with clear weather conditions using Geospatial Information System (GIS) and Digital Surface Model (DSM). Based on the proposed system, the result is corrected by the value of solar radiation database with weather information from 1981 to 2009 provided by NEDO (New Energy and Industrial Technology Development Organization). This system has been derived the simulation result of real time solar radiation considering the surrounding area of the solar radiation meter. In this research, it has been constructed a solar radiation database with fine weather conditions as the basis for deriving the necessary solar radiation simulation results due to various situations. It also has been constructed a system for supporting the prediction of photovoltaic power generation that calculates the necessary solar radiation amount in accordance with the situation from the insolation amount database. Furthermore, it has been analyzed the solar radiation analysis result calculated by the proposed system. In this research, it is proposed some feasible systems when applied to solar radiation simulation system was constructed for photovoltaic systems in agriculture field.
\end{abstract}

Keywords: GIS(Geographic Information System); DSM(Digital Surface Model); Solar Radiation; Solar Energy; Cloud computing; Database

\section{Abbreviations}

GIS: Geographic Information System; DSM: Digital Surface Model; NEDO: New Energy and Industrial Technology Development Organization.

\section{Introduction}

Japan has introduced a fixed power purchase price system in recent years due to the rapid growth of solar power generation and the reduction costs of photovoltaic panels. According to a survey conducted by the Ministry of Economy, Trade and Industry, the average of the fixed power purchase price is about $38,000(\mathrm{JPY} / \mathrm{kW})$ per year between 2010 and 2012, and this trend will continuously increase in the future. As a result, it is expected that introduction of a solar power generation system will continue growing in the nearly future [1].

As the amount of solar power generation is influenced by weather and shadows, various problems are occurring from the effect of weather and shadows. The first issue is the impact on the power grid due to rapid weather changes. The second issue is that it is not possible to obtain the amount of power generation as expected 
after an introduction because it is unknown how much the amount of power generation can actually be obtained before the introduction. This is the effect on individuals and corporations scheduled to the introduction of photovoltaic power generation systems. Such problems can be solved by considering the influence of shadows of buildings and trees. The data of solar radiation amount should contain the influence of shadows of buildings and trees [2]. In addition, it is necessary to provide solar radiation simulation results tailored to each purpose.

In order to investigate the influence on the power grid, it is necessary to have the solar radiation simulation data that can predict the situation in the near future, such as after 15 minutes from the real time data. In addition, those who are planning to introduce solar power generation systems need the solar radiation amount simulation data that considers the influence of the past weather on yearly solar radiation and monthly solar radiation. Our research team has been conducting yearly and monthly solar radiation analysis with clear weather conditions using Geospatial Information System (GIS) and Digital Surface Model (DSM). Based on the proposed system, the result is corrected by the value of solar radiation database with weather information from 1981 to 2009 provided by NEDO [3]. This system has been derived the simulation result of real time solar radiation considering the surrounding area of the solar radiation meter.

In this simulation system, GIS raster data was used. Raster data has a structure that create a value into the mesh of the image while it is not suitable for database construction in GIS. On the other hand, cloud computing technologies such as hybrid clouds have become widespread recently [4]. Therefore, although this simulation system is suitable for use in desktop GIS, it is not suitable for providing a service using cloud computing in the future.

In this research, a method to use vector data of GIS was constructed for the purpose of database creation. It has been constructed a solar radiation database with fine weather conditions as the basis for deriving the necessary solar radiation simulation results due to various situations. It also has been constructed a system for supporting the prediction of photovoltaic power generation that calculates the necessary solar radiation amount in accordance with the situation from the insolation amount database. Furthermore, it has been analyzed the solar radiation result calculated by the proposed system.

Solar radiation affects the growth of plants such as fruits and vegetables. Then, it aims at applying the solar radiation amount simulation system constructed in order to apply to photovoltaic power generation to the field of agriculture.

\section{Materials and Methods}

\section{GIS utilization overview}

GIS is a technology for the creation, management representation, search, analysis and sharing of geospatial information [5]. Figure 1 shows the ability of the system to construct a model for the real world on the computer. GIS manages data in a film called layer. This layer consists of position information and attributes information. As shown in figure 2, GIS constitutes the real world model by superimposing layers. This makes it possible to grasp the geographical distribution and geographical relationship data. Therefore, it is possible to grasp the geographical distribution and geographical relationship of GIS data. Data used in GIS is called geospatial data, with the existence of a very big data. Moreover, GIS has a variety of functions. Typical features and geospatial data of GIS are shown in the following figure 3.

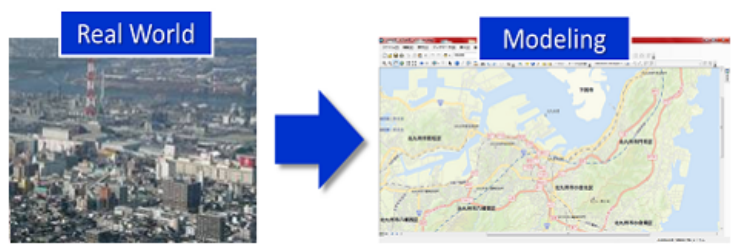

Figure 1: GIS image.

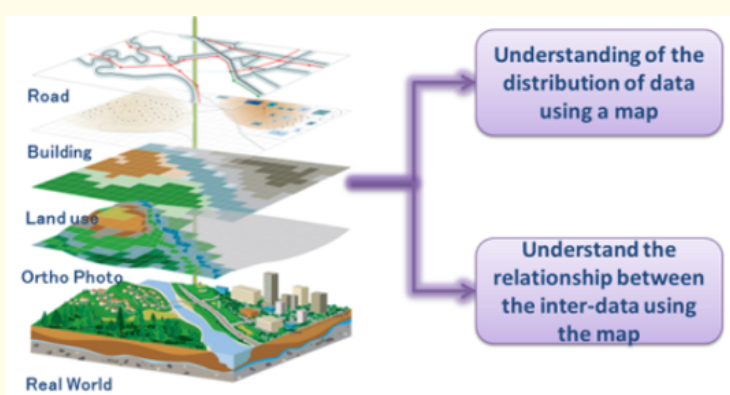

Figure 2: The basic principle of GIS.

\section{Geospatial data}

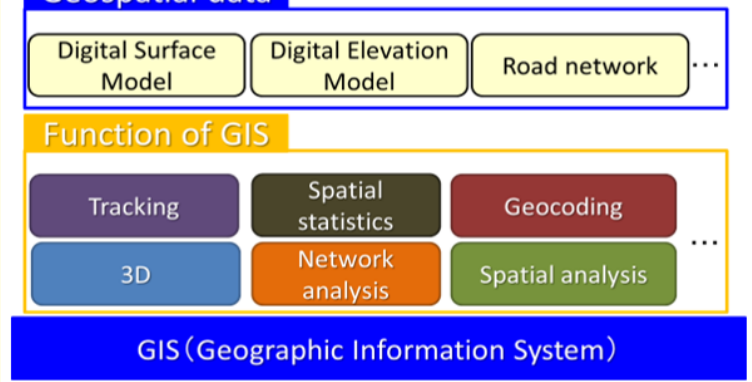

Figure 3: Geospatial data-function of GIS. 
In this figure, Digital Surface Model (DSM) is considering the height of trees and buildings, while Digital Elevation Model (DEM) representing ground surface and the road network providing roads details. Tracking function handles the trajectory of the acquired position information by GPS. Spatial statistics functions aggregate the objects in the view. Geocoding is responsible for coding the text address. 3D function handles the three-dimensional data. Network analysis function performs the analysis of the network data. Finally, Spatial analysis function analyzes the events which might occur in the targeted area [6].

The data that is used for GIS is divided into raster data and vector data. Raster data is a data format suitable for expressing a phenomenon in which space changes continuously [7]. Examples of raster data include aerial photographs, altitude data (DEM and DSM), results of solar radiation amount simulation, and etc. The overview of raster data is shown in figure 4. Vector type is a data format suitable for expressing features with definite position and boundary [7]. Vector data is roughly divided into (1) point, (2) line, (3) polygon. The image of vector data is shown in figure 5.

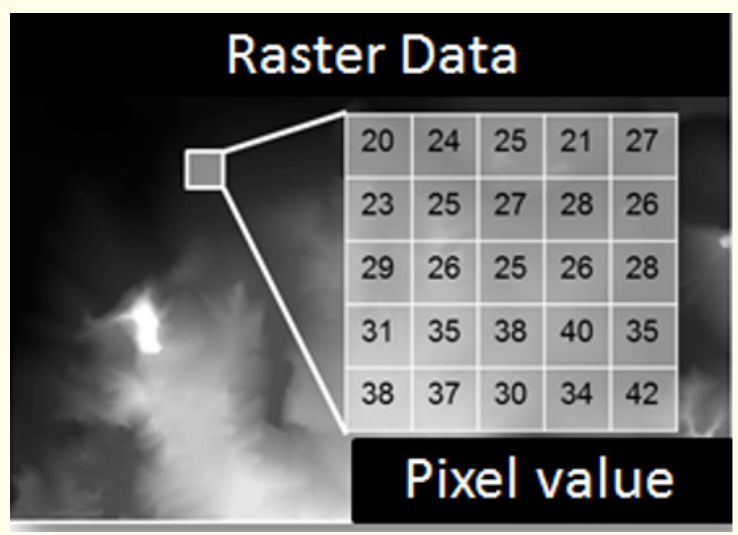

Figure 4: The overview of raster data.

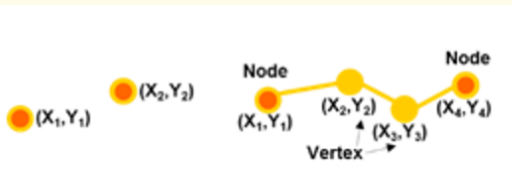

(1) Point

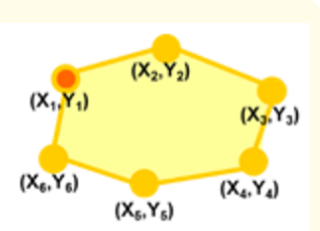

(3) Polygon
Figure 5: The image of vector data.

\section{Outline of the previous system}

In the solar radiation amount simulation system, it has outputted as raster data by the method shown in figure 6 which takes the direct solar radiation and scattered solar radiation into consideration [2]. In addition, the result of solar radiation amount simulation using the output raster data is shown in figure 7 . The green zone indicates that the amount of solar radiation is small and the red zone indicates that the amount of solar radiation is large.

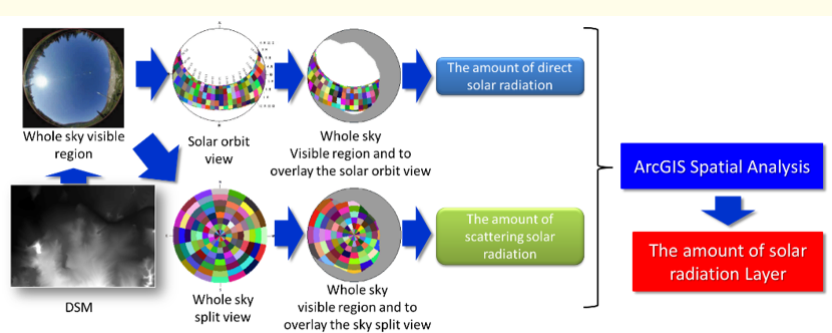

Figure 6: The overview of the previous system.

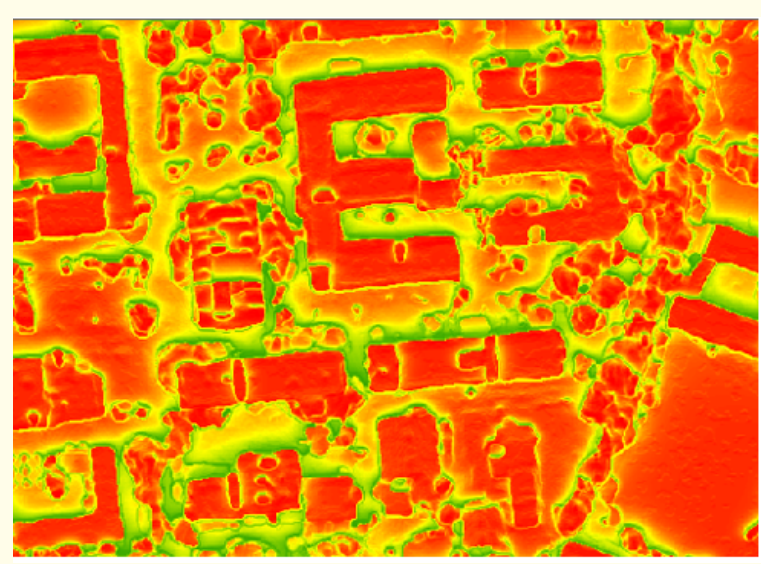

Figure 7: The result of solar radiation by year.

\section{System overview}

The proposed model using GIS that was constructed in this research is composed of the following three functions. Function of converting the raster data of solar radiation amount simulation to vector data Function of constructing the Data Base (DB) by combining vector data and vector data with a table Function of correcting the value of the DB with the value of the NEDO and the amount of solar radiation meter.

The flowchart diagram of this model is shown in figure 8. 


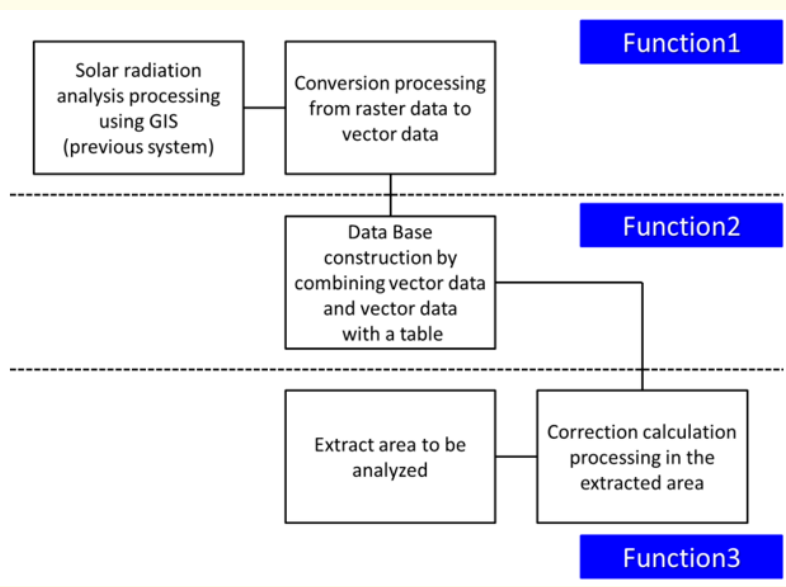

Figure 8: Function of the model and flowchart diagram.

\section{Research scope}

In this paper, it is constructed the Data Base (DB) by converting raster data of simulation results of the amount of annual solar radiation and the amount of monthly solar radiation in the area of Tobata Ward Kitakyushu City, Japan, into vector data. Afterwards, the area for correction is extracted and corrected with the DB value of NEDO. The target of this research is supposed to be a consumer planning to install a photovoltaic power generation system. It is analyzed how much the solar radiation falls into the solar power generation system installed by the consumer.

Function of converting the raster data of solar radiation amount simulation to vector data (Function 1)

In previous studies, it has been constructed a system to analyze solar radiation using GIS and DSM. DSM is elevation data with the height of buildings and trees [8]. Figure 9 shows the difference between DSM and DEM.

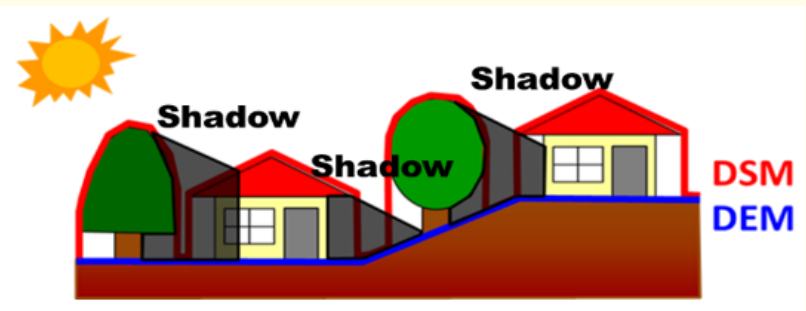

Figure 9: The difference between DSM and DEM.

The result has been analyzed by this system called the raster data as shown in Fig.7. This raster data is converted into vector data using the conversion function of GIS. Raster data has several values for each mesh. When the conversion process is applied, attribute information of vector data will have a mesh value of raster data. Figure 10 shows the raster data before conversion, vector data after the conversion and attributes information (i.e., point data). The red frame is the amount of solar radiation installed in the attribute information of point data. In addition, this point data is stored in ArcGIS File-Geo-DataBase (FGDB).

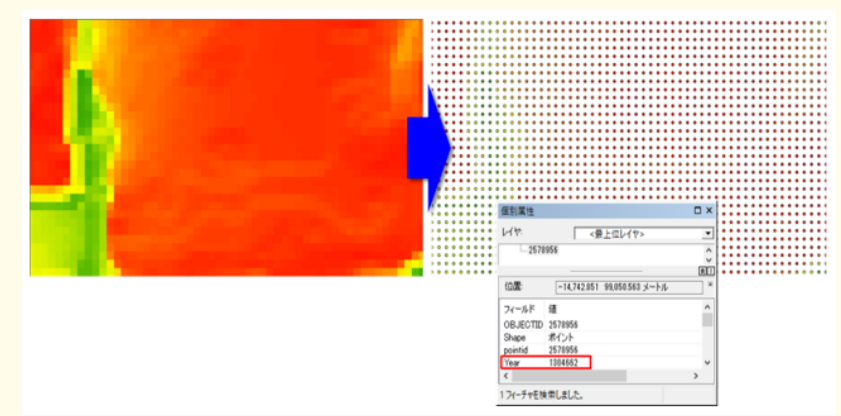

Figure 10: Before and after the conversion and attributes information.

Function of constructing Data Base by combining vector data and vector data with a table (Function 2)

The data stored in FGDB of ArcGIS can be combined data by using the function of a joined table. Joined table is used to attach fields from one table to fields in another table through attributions or fields that are common to both tables. The image diagram is shown in figure 11 [9]. Figure 12 shows the result of combining the annual solar radiation amount and the solar radiation amount of each month using this function to DB. The red frame in Figure 12 shows the combined year and monthly solar radiation. The attributed information of DB constructed in this research is shown in table 1.

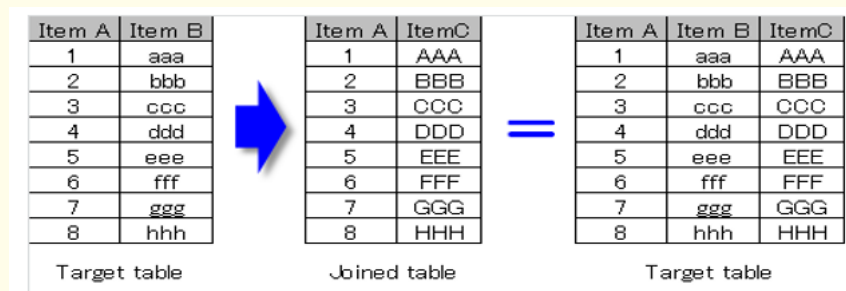

Figure 11: The image diagram of joined table. 


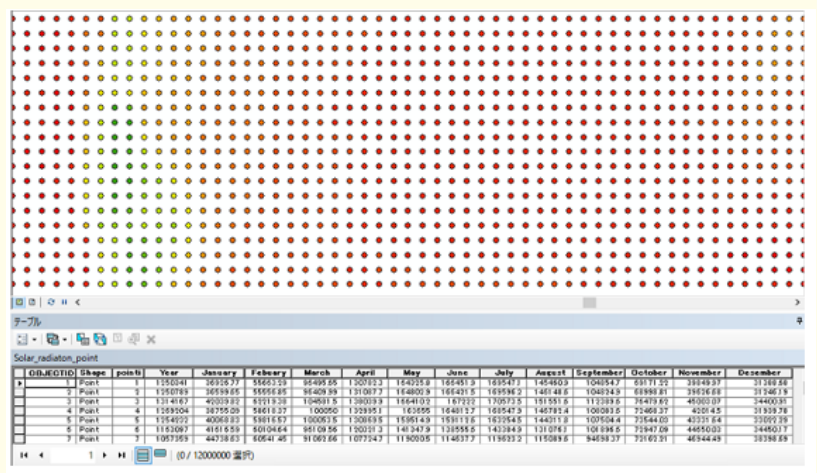

Figure 12: DB value of combining the annual solar radiation amount and the solar radiation amount of each month.

\begin{tabular}{|l|c|c|}
\hline No & Item Name & Data Type \\
\hline 1 & Yearly & Double \\
\hline 2 & January & Double \\
\hline 3 & February & Double \\
\hline 4 & March & Double \\
\hline 5 & April & Double \\
\hline 6 & May & Double \\
\hline 7 & June & Double \\
\hline 8 & July & Double \\
\hline 9 & August & Double \\
\hline 10 & September & Double \\
\hline 11 & October & Double \\
\hline 12 & November & Double \\
\hline 13 & December & Double \\
\hline
\end{tabular}

Table 1: The attributed information of the amount of solar radiation DB.

Function to extract necessary area and capture weather conditions (Function 3)

The area for analysis is drawn with polygon data known as the vector data of GIS. In this research, it is targeted the photovoltaic panels installed at Building No. 10 of Tobata Campus, Kyushu Institute of Technology (Kyutech). The blue frame in figure 13 shows the target area of this research. The area is $24.970003 \mathrm{~m}^{2}$ measured by GIS.

Next, CLIP process of GIS has been used as a method of extracting data of the target area from the solar radiation amount DB. In this study, it is clarified that the GIS is suitable for extracting data of a specific area from the DB on the map. Figure 14 shows the extraction result of the data of the target area using the CLIP function from the solar radiation amount DB.

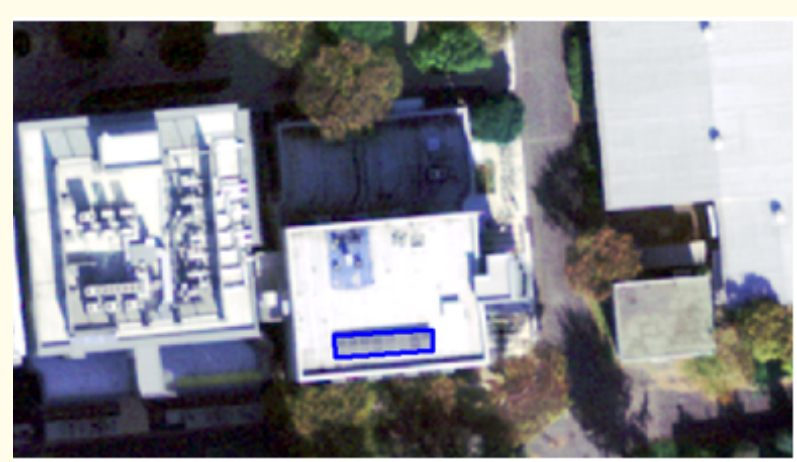

Figure 13: The image of analysis area.

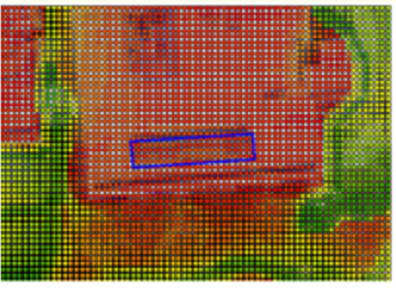

(a) Before extraction

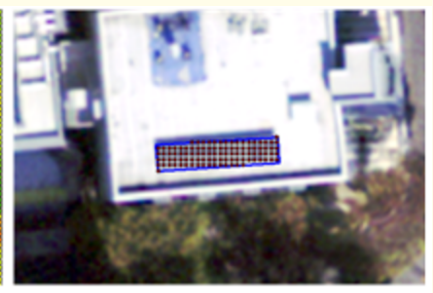

(b) After extraction
Figure 14: A result of using CLIP function.

Afterwards, a method for correcting the yearly solar radiation amount data of the area extracted by the value of the DB based on NEDO will be described. The data of this map is the amount of solar radiation average value for one day or month or year, which is calculated from the measured results of 1981-2009 [3]. In other words, this data has the elements of the weather. The MAX value of the amount of solar radiation analysis results using GIS has been corrected by the value of NEDO. In addition, it is possible to consider the weather conditions on the amount of solar radiation analysis by correcting the value of NEDO. This process can be described as follow.

Firstly, the amount of solar radiation analysis process using the GIS in the sunny weather has been evaluated. The amount of solar radiation map by NEDO is $13 \mathrm{MJ} / \mathrm{m}^{2}$. day represented by the red circle as shown in figure 15 . Therefore, the total amount of solar radiation for one year can be calculated by (1) as follows:

$13 \mathrm{~J} / \mathrm{m}^{2} \times 365$ day $\times 0.2778=1318.161 \mathrm{kWh} / \mathrm{m}^{2}(1)$ 


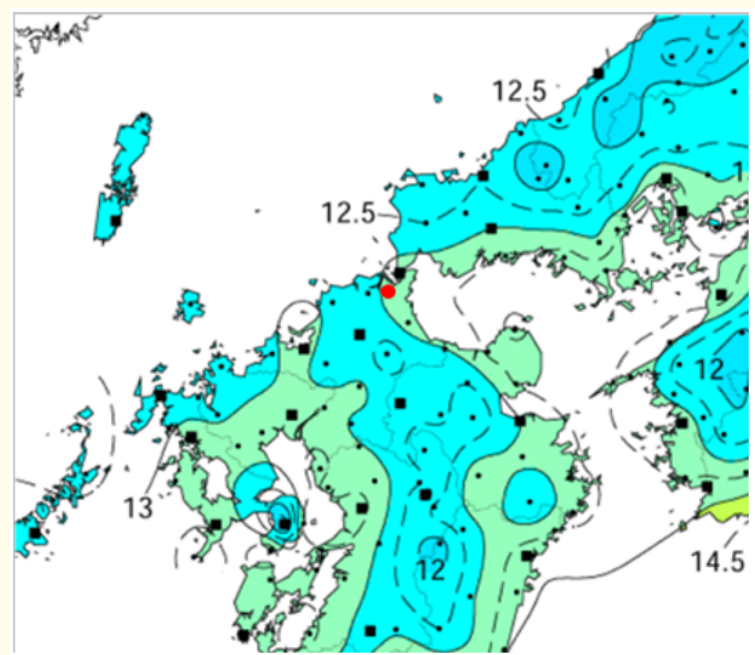

Figure 15: The amount of solar radiation map by NEDO.

In addition, the maximum value using the analysis results of the Kyutech area or the amount of solar radiation analysis is $1474.9 \mathrm{kWh} / \mathrm{m}^{2}$. This maximum value is re-calculated as the value of the NEDO [3]. The correction is performed by multiplying the data of the solar radiation amount DB with the corrected value of 1318.161/1474.9. The correction method uses the field calculation function of GIS. The result of field calculation is shown in figure 16 Next, the average value of the solar radiation amount in the target area is obtained. For the method of finding the average value, we used the statistical function of GIS. From the processing result of figure 17, the annual solar radiation amount is $1142779.615 \mathrm{kWh} /$ $\mathrm{m}^{2}$. By multiplying the area of the panel by $24.970003 \mathrm{~m}^{2}$, the annual amount of solar radiation entering the solar power generation panel is $28535210.29 \mathrm{kWh}$.

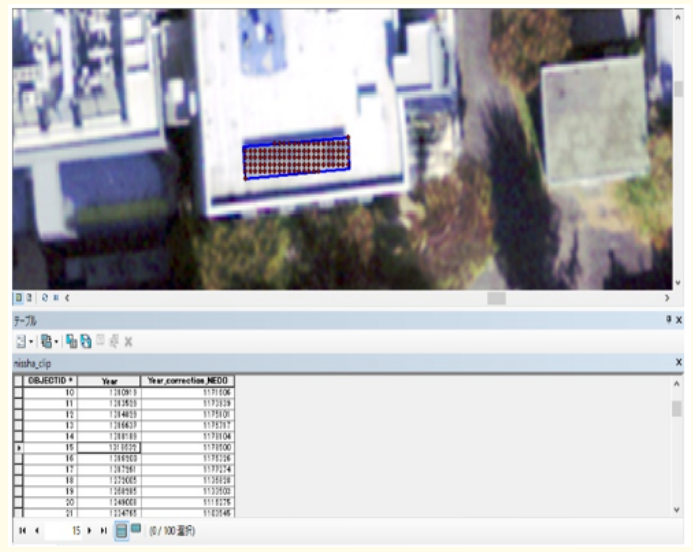

Figure 16: The result of field calculation.

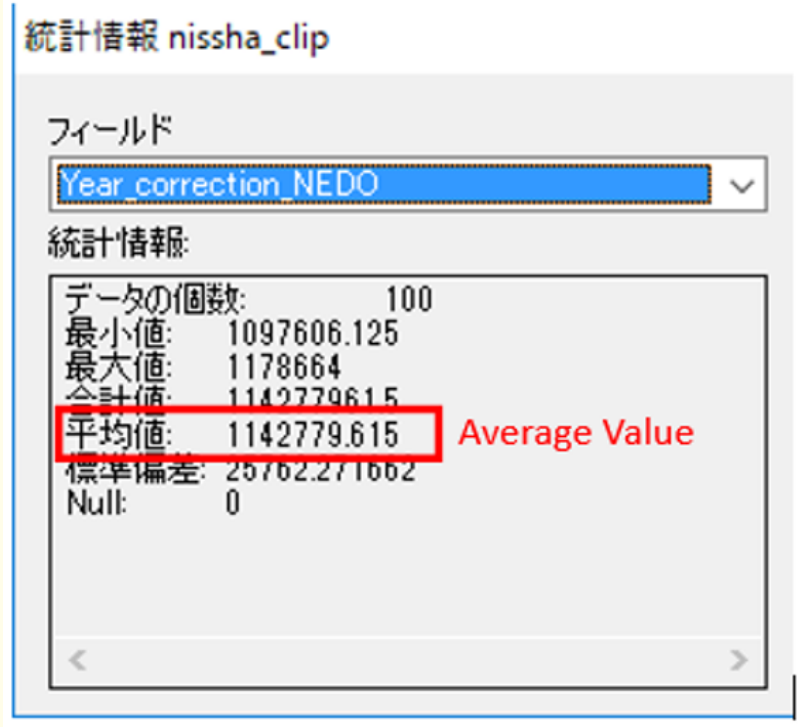

Figure 17: The average value of annual solar.

\section{Results and Discussion}

The solar radiation simulation system up to the previous section was constructed to solve the problems in the electric power energy field. In the amount of solar radiation simulation system using GIS, simulation can be performed according to users need such as annual, monthly, arbitrary period, time unit.

This mechanism can also be used in the agricultural field. This paper proposes what kind of system can be realized when this system is used in the agricultural field.

Firstly, it is possible to construct a system that indicates whether the necessary amount of solar radiation can be obtained if the period of plant cultivation and the necessary amount of solar radiation are determined on the land where the plant is to be newly cultivated. The overview of the system is shown in figure 18.

The amount of precipitation, solar radiation, temperature, and cultivation period required for growth for each plant are stored in a database. When the area and period for cultivation on the GIS are input, it is possible to construct a system that proposes plants that can be cultivated. The overview of the system is shown in figure 19.

In order to realize these systems, it is necessary to conduct joint research with agricultural experts. 


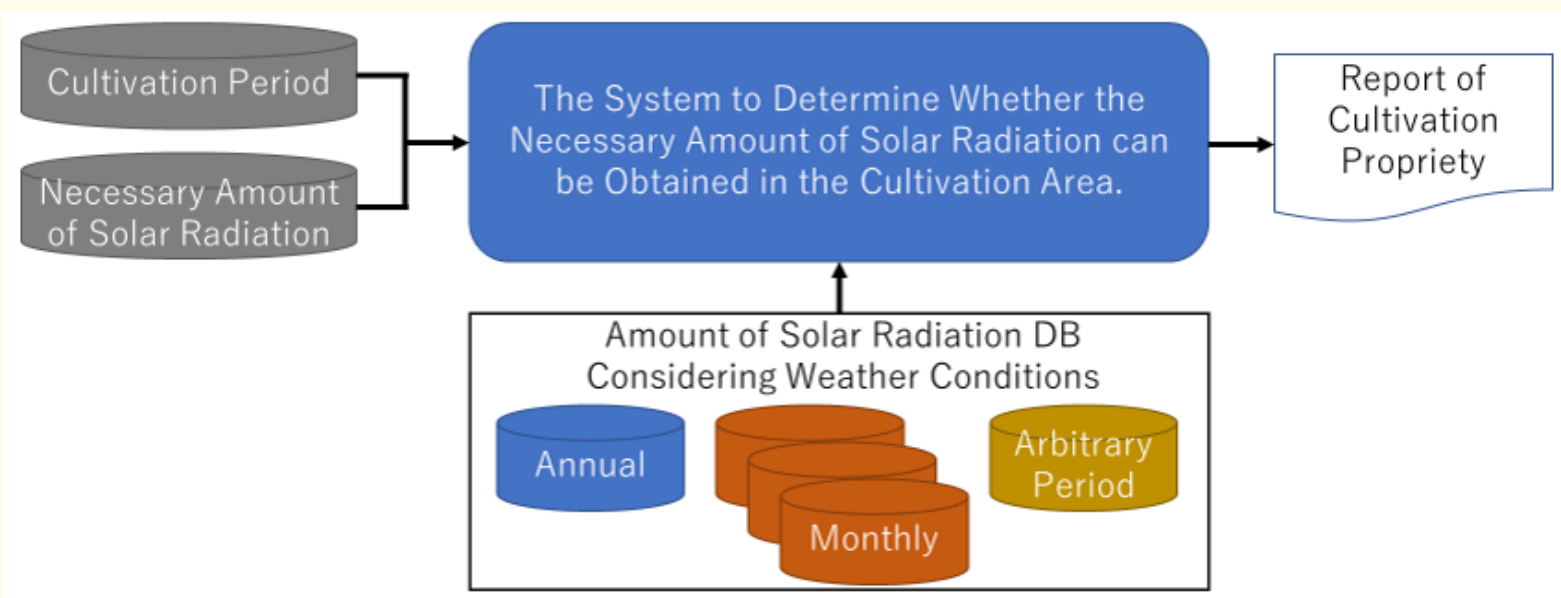

Figure 18: Overview of cultivation consideration support system.

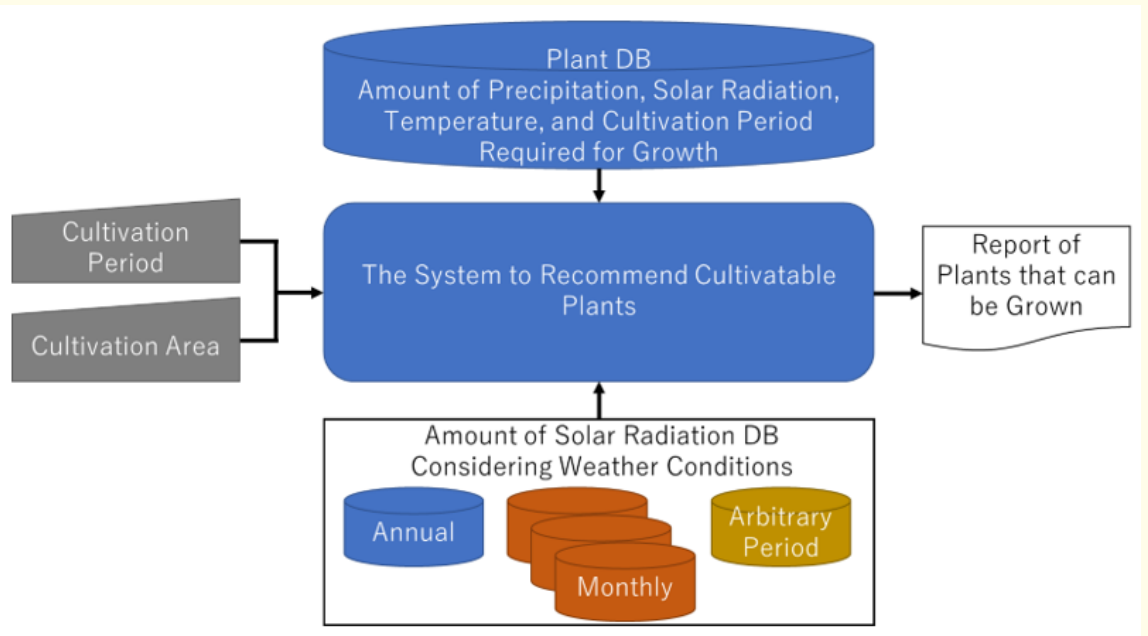

Figure 19: Overview of System to recommend cultivatable Plants.

\section{Conclusion}

This research has constructed the new method to convert raster data of the simulation result of the amount of solar radiation constructed in previous research to vector data and constructed database. It has been shown the method of extracting an area for analyzing the amount of solar radiation from this database and correcting the amount of solar radiation in that area using the solar radiation amount database from NEDO.

In this research, as the result of the solar radiation amount is stored in the database, the value of database from NEDO is used for correction, while other medium values such as solar radiation meter can be used. In addition, although the yearly solar radiation amount and monthly solar radiation amount are converted to database, it is a mechanism that can also convert the data on the time axis according to the provided services, such as on a daily or hourly basis, into the database.

The further work is to construct the Web services using this DB and cloud computing, such as the prediction service of power generation amount during the implementations of solar power system and power generation prediction service of solar power system based on solar radiation forecast data. 
Furthermore, it has been proposed the two systems that can be constructed when the solar radiation simulation system is applied to the agricultural field.

In the future, we plan to predict the amount of solar radiation in the near future by combining the omnidirectional camera image and the solar radiation DB built by our research team. In addition, the proposal system will be realized through joint research with experts in the agricultural field.

\section{Acknowledgements}

I would like to thank the staffs of Kitakyushu city who provided some data for this research. I also thank you for all students in the laboratory who carried out research together. The system configuration diagram is shown in Fig. 18.

\section{Conflict of Interest}

I have no economic interests or conflicts of interest.

\section{Bibliography}

1. Atsushi Shiota., et al. "Guide Construction of an Efficient Inspection, Maintenance and Asset Management of Photovoltaic Power Generation System Using GIS”. Energy Procedia (2016).

2. Atsushi Shiota., et al. "Development and Public Release of Solar Radiation Map for Effective Use of Solar Energy Based on GIS with Digital Surface Model". CPESE (2015).

3. Atsushi SHIOTA., et al. "GIS Utilization to Support the Application of Supplying Electric Power to Temporary Housing with PV and Energy Storage". in Proc. International Conference on Electrical Engineering (ICEE), (2016).

4. A Shiota., et al. "Sharing Regional Information with Spatial Information between Public and Proactive Citizens Based on Technology of Hybrid Cloud - Contribution for Disaster Reduction by G-motty of city of Kitakyushu". Geospatial information and technology association (GITA) (2015).
5. Huisman and R. A. D. By, Principles of Geographic Information Systems, Enschede, The Netherlands: ITC (2009).

6. A Shiota., et al. "Construction of transporting system the electric power by using EV as mobile battery system in during black out of power grid by disasters". in Proc. International Conference on Electrical Engineering (ICEE), 2015.

7. A Shiota. Utilization of GIS in power system Master's thesis at Kyushu Institute of Technology, Japan (2014).

8. A Shiota., et al. "The outline of the photovoltaic simulation system using GIS (in Japanese)". Committee of Joint Conference of Electrical and Electronics Engineers in Kyushu (2013).

9. Attribute combination between tables (ESRI website).

\section{Volume 3 Issue 10 October 2019 \\ (c) All rights are reserved by Atsushi Shiota., et al.}

